\title{
Interaction analyses based on growth parameters of GWAS between Escherichia coli and Staphylococcus aureus
}

Yajing Liang ${ }^{3 \dagger}$, Beibei Li ${ }^{3 \dagger}$, Qi Zhang ${ }^{3}$, Shilong Zhang ${ }^{2,3}$, Xiaoqing He $\mathrm{e}^{1,2,3^{*}} \mathbb{0}$, Libo Jiang ${ }^{1,2,3^{*}}$ and Yi Jin $2,3^{*}$

\begin{abstract}
To accurately explore the interaction mechanism between Escherichia coli and Staphylococcus aureus, we designed an ecological experiment to monoculture and co-culture E. coli and S. aureus. We co-cultured 45 strains of E. coli and $S$. aureus, as well as each species individually to measure growth over $36 \mathrm{~h}$. We implemented a genome wide association study (GWAS) based on growth parameters $(\lambda, R, A$ and $s)$ to identify significant single nucleotide polymorphisms (SNPs) of the bacteria. Three commonly used growth regression equations, Logistic, Gompertz, and Richards, were used to fit the bacteria growth data of each strain. Then each equation's Akaike's information criterion (AIC) value was calculated as a commonly used information criterion. We used the optimal growth equation to estimate the four parameters above for strains in co-culture. By plotting the estimates for each parameter across two strains, we can visualize how growth parameters respond ecologically to environment stimuli. We verified that different genotypes of bacteria had different growth trajectories, although they were the same species. We reported 85 and 52 significant SNPs that were associated with interaction in E. coli and S. aureus, respectively. Many significant genes might play key roles in interaction, such as yjjW, dnaK, aceE, tatD, ftsA, rclR, ftsK, fepA in E. coli, and scdA, trpD, sdrD, SAOUHSC_01219 in S. aureus. Our study illustrated that there were multiple genes working together to affect bacterial interaction, and laid a solid foundation for the later study of more complex inter-bacterial interaction mechanisms.
\end{abstract}

Keywords: Interaction mechanism, Growth parameters, Growth trajectories, Significant SNPs

\section{Introduction}

There are extremely complex interactions between organisms and their environment, which play a crucial role in nature, particularly in microbial environments (Grativol et al. 2017; He et al. 2017; Madsen et al. 2018; Pires et al. 2015; van Overbeek and Saikkonen 2016). A large number of strains exist in co-cultured complexes of bacteria (Cairns et al. 2018), and they form diverse and dynamic communities with complex interaction mechanisms

\footnotetext{
${ }^{*}$ Correspondence: lenahe@bjfu.edu.cn; jianglibo0534@163.com; yijin@bjfu. edu.cn

${ }^{\dagger}$ Yajing Liang, Beibei Li and Qi Zhan contributed to this work equally

${ }^{1}$ Beijing Advanced Innovation Center for Tree Breeding by Molecular

Design, Beijing Forestry University, Beijing 100083, China

${ }^{3}$ College of Biological Sciences and Technology, Beijing Forestry

University, Beijing 100083, China

Full list of author information is available at the end of the article
}

including mutualism, antagonism, parasitism, commensalism, and amensalism (Widder et al. 2016; Xiao et al. 2017). Microbial interactions have rarely been experimentally validated due to the challenges of duplicating ecologically relevant conditions in a laboratory environment and the limited ability to culture all members of a complex multispecies microbiome (Kastman et al. 2016). Therefore, we constructed a simplified experimental system to simulate culture conditions.

A genome-wide association study (GWAS) with longitudinal phenotypes provides a novel platform to identify genetic variant associations and how they change over time (Sikorska et al. 2018). The emergence of GWAS has accelerated the development of bacterial gene function research, which enables the screening of interaction-associated loci (Lees et al. 2016; Ning et al. 2017; Sheppard et al. 2013). Therefore, the application
Springer Open (c) The Author(s) 2021. This article is licensed under a Creative Commons Attribution 4.0 International License, which permits use, sharing, adaptation, distribution and reproduction in any medium or format, as long as you give appropriate credit to the original author(s) and the source, provide a link to the Creative Commons licence, and indicate if changes were made. The images or other third party material in this article are included in the article's Creative Commons licence, unless indicated otherwise in a credit line to the material. If material is not included in the article's Creative Commons licence and your intended use is not permitted by statutory regulation or exceeds the permitted use, you will need to obtain permission directly from the copyright holder. To view a copy of this licence, visit http://creativeco mmons.org/licenses/by/4.0/. 
of GWAS to bacteria opens new horizons for exploring the interaction mechanisms of bacteria. Many bacterial phenotypes can be linked to the presence or absence of significant genes, which partly explains different responses to similar environmental conditions. There is great potential to investigate environmentally or industrially relevant phenotypes as well (Chen and Shapiro 2015). Recently bacterial GWAS have overcame some limitations of the traditional genetic association studies, such as sample sizes and population structure, which is able to associate genetic variation in genomes with phenotypes to analyze genetic mechanisms (Lees et al. 2016). Studies on single-nucleotide polymorphism (SNPs) are a starting point for identifying genes that may be responsible for specific phenotypes (Hall 2014). In our lab, we have applied GWAS analyses to find many significant genes in $E$. coli and $S$. aureus and have explored the phenotypic plasticity of S. aureus (He et al. 2017; Jiang et al. 2018; Rong et al. 2019). Our analyses provide a strong basis for interaction experiments of bacteria in future studies.

Currently most GWAS methods are based on simple genotype phenotype analyses, and dynamic growth is treated statically. Gene-gene and gene-environment interactions are time dependent and temporal dynamical interactions require efficient modeling (Fan et al. 2012). Complex phenotypes arise as a function of time, so we cannot capitalize on full information of phenotypic expression. A previous study integrated GWAS and functional aspects of dynamic traits, proposing a novel statistical approach called functional GWAS (fGWAS) (Das et al. 2011). It is able to address the limitations of traditional GWAS methods, and uses growth trajectories as a phenotype to conduct GWAS, which remarkably increases the power for gene detection. In this way, fGWAS can capture genotypic differences at the level of phenotypic curves according to growth parameters (Li et al. 2015; Wei et al. 2018). On this basis, a previous study fit growth equations to leaf area and leaf area mass growth data of an individual recombinant inbred line (RIL), and developed a bivariate model for mapping growth parameters of the two traits (Wei et al. 2018).

In this study, we extended the application of GWAS based on growth parameters to the study of bacterial interactions, applying functional mapping and statistical analyses to express bacterial growth phases. Then we simulated the living environment of $E$. coli and $S$. aureus to study their dynamic interactions and to target phenotypic traits. The aim of our study is to explore the genetic mechanism of bacterial interaction, therefore, lay a scientific theoretical foundation for microbial community analyses.

\section{Materials and methods}

\section{Experimental design}

We applied statistical analyses to study the growth interactions of E. coli and S. aureus in a common environment and explore important gene mechanisms. Based on co-cultures, we implemented a bivariate statistical procedure to map and identify SNPs. Using these SNPs, we predicted bacterial growth by estimating cultivar-specific growth parameters and incorporating these parameters into a mapping framework.

All the strains of E. coli and S. aureus are from National Infrastructure of Microbial Resources, China, and these are detailed in previous work (Jiang et al. 2018) (Additional file 1: Table S1). We separately monocultured and co-cultured the strains under different conditions, although temperature, culture time, and environment were kept constant.

We investigated relationships by measuring the abundance of each strain repeatedly at multiple times. We randomly paired 45 strains of E. coli and 45 strains of $S$. aureus, and cultured each pair in a $50 \mathrm{~mL}$ Erlenmeyer flask with three parallel treatments, following a previous study (Jiang et al. 2018). Then we obtained the growth data of the strains in monoculture and co-culture as phenotype data (Additional file 2: Table S2).

\section{Whole-genome sequencing}

Whole-genome sequencing was performed on an Illumina HiSeq2000/2500 platform at Novogene (Novogene, Beijing, China) using E. coli str. K-12 substr. MG1655 and S. aureus subsp. aureus NCTC 8325 as the reference strains, respectively. More details can be found in a previous study (He et al. 2017).

\section{Data fitting}

Bacterial growth follows a standard s-shaped curve. A typical growth curve spans three continuously connected phases: the lag phase (where the growth rate emerges from a value of zero), the exponential phase (during which the rate of growth accelerates to a maximal value and then decelerates to a minimal value, cells are typically in their healthiest state and thus are most desirable for enzymes or other cell components), and the stationary phase (growth rate continues to decelerate to zero and bacteria reached a stable state). Many mathematical equations have been derived to reflect the features of a growth curve, including Gompertz, logistic, and Richards equations. Let $g(t)$ denote the growth of a trait at time $t$. These equations are expressed as 


$$
g(t)= \begin{cases}A \cdot \exp \left\{-\exp \left[\frac{R \cdot e}{A}(\lambda-t)+1\right]\right\} & \text { Gompertz } \\ \frac{A}{1+\exp \left[\frac{4 R}{A}(\lambda-t)+2\right]} & \text { Logistic } \\ A\left\{1+s \cdot \exp (1+s) \cdot \exp \left[\frac{R}{A}(1+s)\left(1+\frac{1}{s}\right)(\lambda-t)\right]\right\}^{\left(-\frac{1}{s}\right)} & \text { Richards }\end{cases}
$$

According to the mathematical equations, we used parameters $\lambda$ (lag time), $R$ (maximum specific growth rate) and $A$ (asymptotic growth) to describe three continuous phases of bacterial growth curves, respectively. Moreover, these three key parameters were used as phenotypic data in GWAS analyses. In the Richards equation $s$ is a shape parameter that describes the curvature of a growth curve (Wei et al. 2018).

First, we used all three growth equations to fit $E$. coli and $S$. aureus monoculture growth trait data at each location using a nonlinear least squares approach. Then we calculated each equation's AIC value. This procedure allows the choice of an optimal growth equation that best fits bacterial growth at a given location, dependent on statistical reasoning. The three parameters mentioned above were estimated from the optimal equation and used as phenotypic traits for subsequent functional mapping.

\section{GWAS model}

We analyzed the associations between SNPs and microbial abundances measured for bacterial populations reared in monocultures and co-cultures. We calculated the $\log _{10}(P$-values $)$ of each association, from which Manhattan plots were derived.

In co-cultures, we used binary correlation coefficients to treat the three parameters as three different periods of phenotypic data combined with genotype data for comparative analyses. We constructed two-dimensional

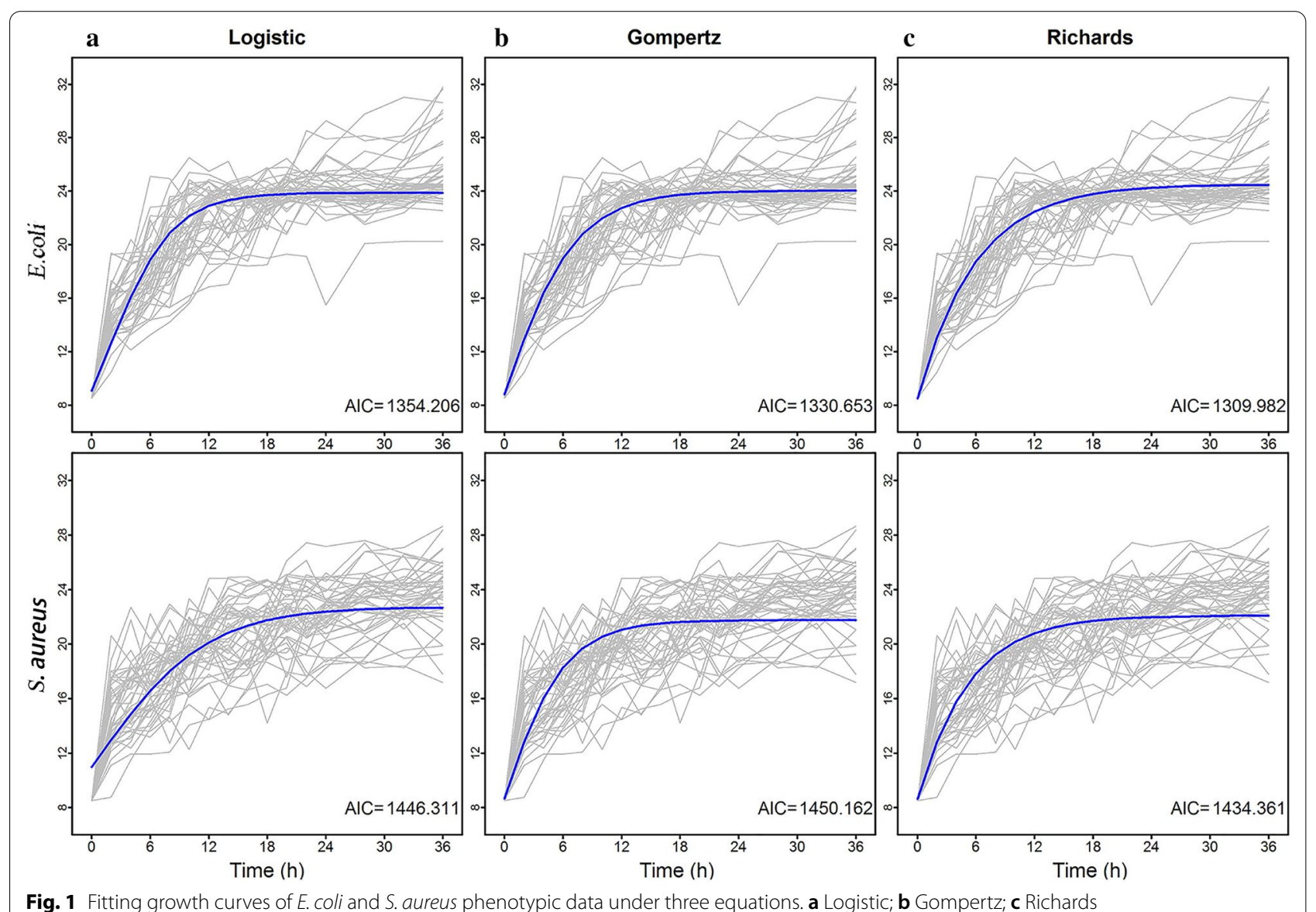

Fig. 1 Fitting growth curves of E. coli and S. aureus phenotypic data under three equations. a Logistic; b Gompertz; c Richards 
Manhattan plots, thereby obtaining significant SNPs of interaction between the two strains under the same culture conditions.

\section{Results}

\section{Data fitting by the growth equations}

Three commonly used regression equations of growth, namely, Logistic, Gompertz and Richards regressions, were used to fit the growth curves of $45 \mathrm{E}$. coli and 45 S. aureus strains (Fig. 1 and Additional file 3: Figure S1). Microbial abundance of individual strains was observed over $36 \mathrm{~h}$. An optimal equation was chosen based on Akaike's information criterion (AIC). Richards regression had a better goodness-of-fit to the mean growth trajectories and thus was used in analyses of phenotypic data and to fit co-culture bacterial growth curves.

\section{Genetic analyses of microbial growth in monocultures} Manhattan plots were obtained by employing GWAS combined with functional mapping of $45 \mathrm{E}$. coli and $45 \mathrm{~S}$. aureus strains to identify polymorphisms associated with different growth phenotypes. Figure 2 shows Manhattan plots for significant SNPs identified in monocultures of each strain. In all, 85 and 97 significant SNPs were beyond the genome-wide critical thresholds determined for E. coli and S. aureus, respectively, and were annotated. Of those, 71 SNPs in E. coli mapped to 67 genes, were associated with growth; 63 SNPs in S. aureus, were mapped to 45 genes (Additional file 4: Table S3). Interestingly, many of the significant SNPs detected in GWAS were distributed in the genomic regions involved in metabolism and regulation.

To demonstrate the biological relevance of the model, we cultured all strains individually in isolated flasks. The microbial abundance of each strain was fitted separately for two alternative genotypes at E3393816 for E. coli and at S994124 for S. aureus (Fig. 3). We found different phenotypic data for each genotype. In E. coli, G genotype strains grew relatively faster than A genotype strains; in S. aureus, $\mathrm{T}$ genotype strains grew faster than $\mathrm{C}$ genotype strains in the exponential phase but grew uniformly in the stationary phase. Therefore, differences in genotypes affect the growth of strains, resulting in phenotypic diversity.

\section{Interaction analyses based on growth parameters in co-culture}

In co-culture we used the Richards equation to fit bacterial growth and the curve fitting for growth data of each strain under co-culture were shown in Additional file 3: Figure S1. The four biologically meaningful growth parameters, $\lambda, R, A$ and $s$, estimated from the Richards equation, were each used as a 'phenotypic trait' for subsequent GWAS analysis. We performed GWAS based on growth parameters to identify significant SNPs between the genotype and phenotype data of E. coli and S. aureus, and combined with the $\mathrm{R}$ package to generate the twodimensional Manhattan plots (Fig. 4). The $x$-axis represents the relative SNP position of $E$. coli, the y-axis represents the relative SNP position of $S$. aureus, and the red dots in the figure represent the significant SNPs affecting the bacterial interaction. According to the corresponding positions of SNPs in the two-dimensional plots, their positions in the genome can be identified and then the significant SNPs in the interaction can be annotated. The $\mathrm{R}^{2}$ value of fitting growth curves of $E$. coli and $S$. aureus in co-culture were shown in Additional file 5: Table S4.
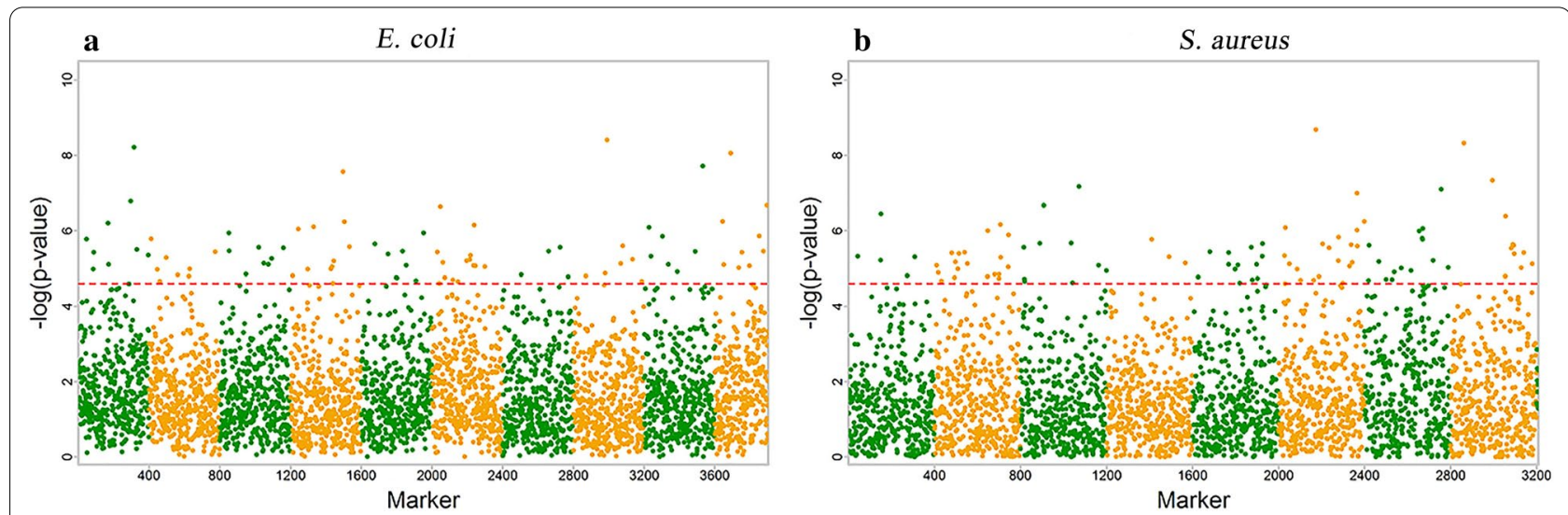

Fig. 2 Manhattan plots of GWAS results for E. coli and S. aureus in monoculture. a E. coli; b S. aureus 

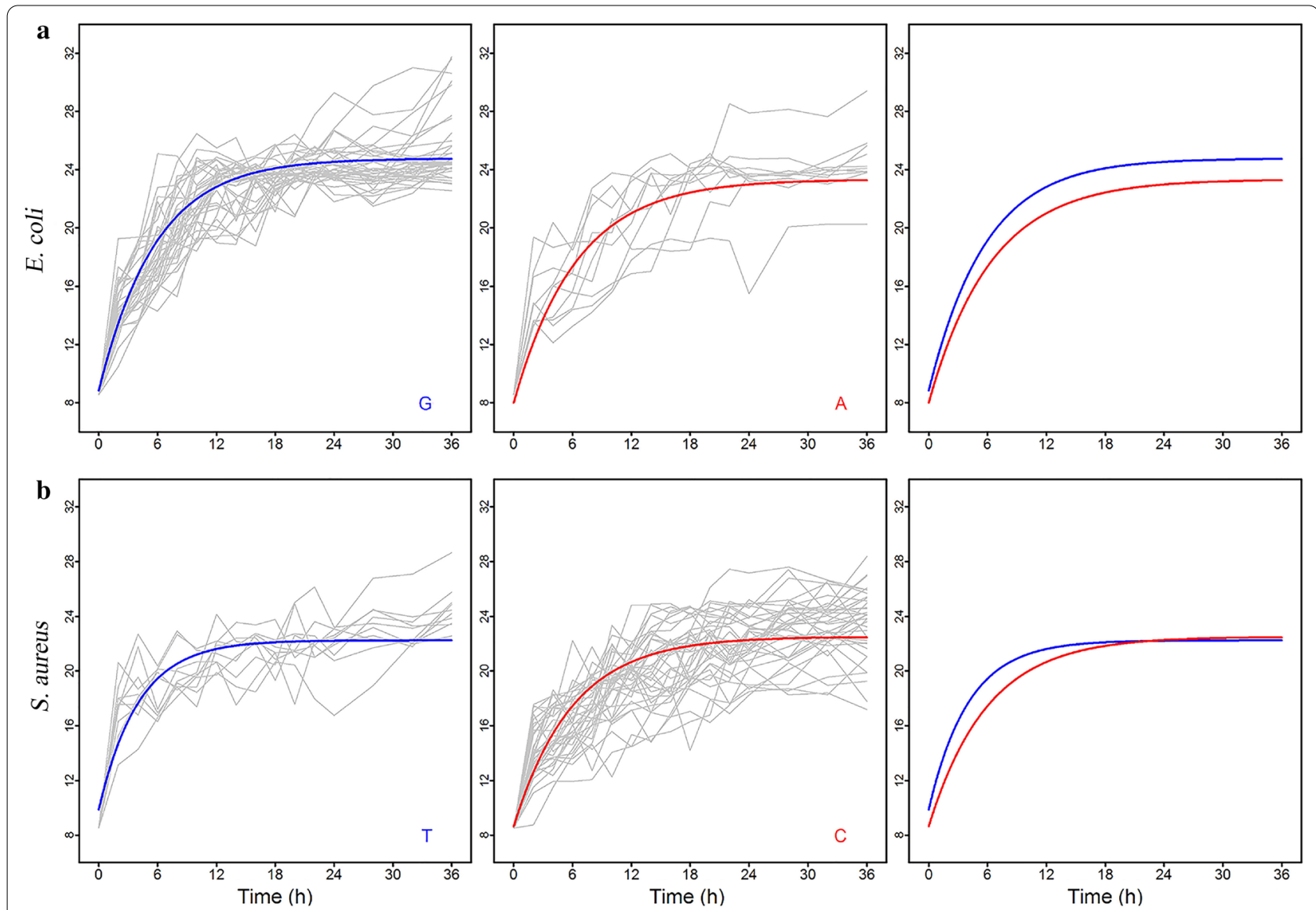

Fig. 3 Fitting growth curves of the most significant SNPs of E. coli (E3393816) and S. aureus (S994124). a E. coli; b S. aureus

\section{Analyses of significant genes in E. coli}

In $E$. coli, there were 5 significant SNPs under the lambda $(\lambda)$ parameter and 12 under the $R$ parameter. Thirty-four significant SNPs were under the $A$ parameter and shape (s) parameters, respectively (Additional file 6: Table S5). Among the significant SNPs in E. coli, eight genes were associated with significant functions in bacterial growth: ace $E$ encodes a pyruvate dehydrogenase $\mathrm{E}_{1}$ component that plays an important role in the preparation stage of the citric acid cycle; $y j j W$ encodes a homolog of pyruvate formate lyase activating enzyme PflA; $d n a K$ functions in the heat shock response; fts $K$ and $f t s A$ are relevant to cell division; tat $D$ encodes $3^{\prime}$ to $5^{\prime}$ ssDNA/RNA exonuclease; the protein which $r c l R$ encodes is a transcriptional activator, and fepA effects ferric enterobactin outer membrane transporter (Table 1).

\section{Analyses of significant genes in S. aureus}

Meanwhile, in $S$. aureus, there were three significant SNPs under the lambda $(\lambda)$ parameter, 13 under the $R$ parameter, and seventeen under the shape $(s)$ parameter. $A$ parameter SNPs were the most diverse, with 19 significant SNPs (Additional file 6: Table S5). In S. aureus, we found many significant genes, such as $s c d A$ encoding a cell wall biosynthesis protein, and $s d r D$ encoding a fibrinogen-binding protein. A hypothetical gene (SAOUHSC_01219) was predicted for the encoded cell wall hydrolase (Table 1). Many significant genes were found to have an important role in the regulation of metabolism and bacterial reproduction and regulation, which may be correlated with evolution or growth performance in co-culture.

\section{Discussion}

Bacterial interaction plays a vital role in the ecosystems (Rivett and Bell 2018). Previous studies illustrated that the changes of phenotypes in bacterial interaction were related to complex systems (such as quorum sensing), and cannot be predicted from analyzing the individual bacteria strain (Madsen et al. 2018). Many researches had used GWAS to unravel the genetic machineries of interspecies interactions in microbes (Berthenet et al. 2018; Collins and Didelot 2018; He et al. 2017; Rong et al. 2019). Wei et al. (2018) found that identification of major 

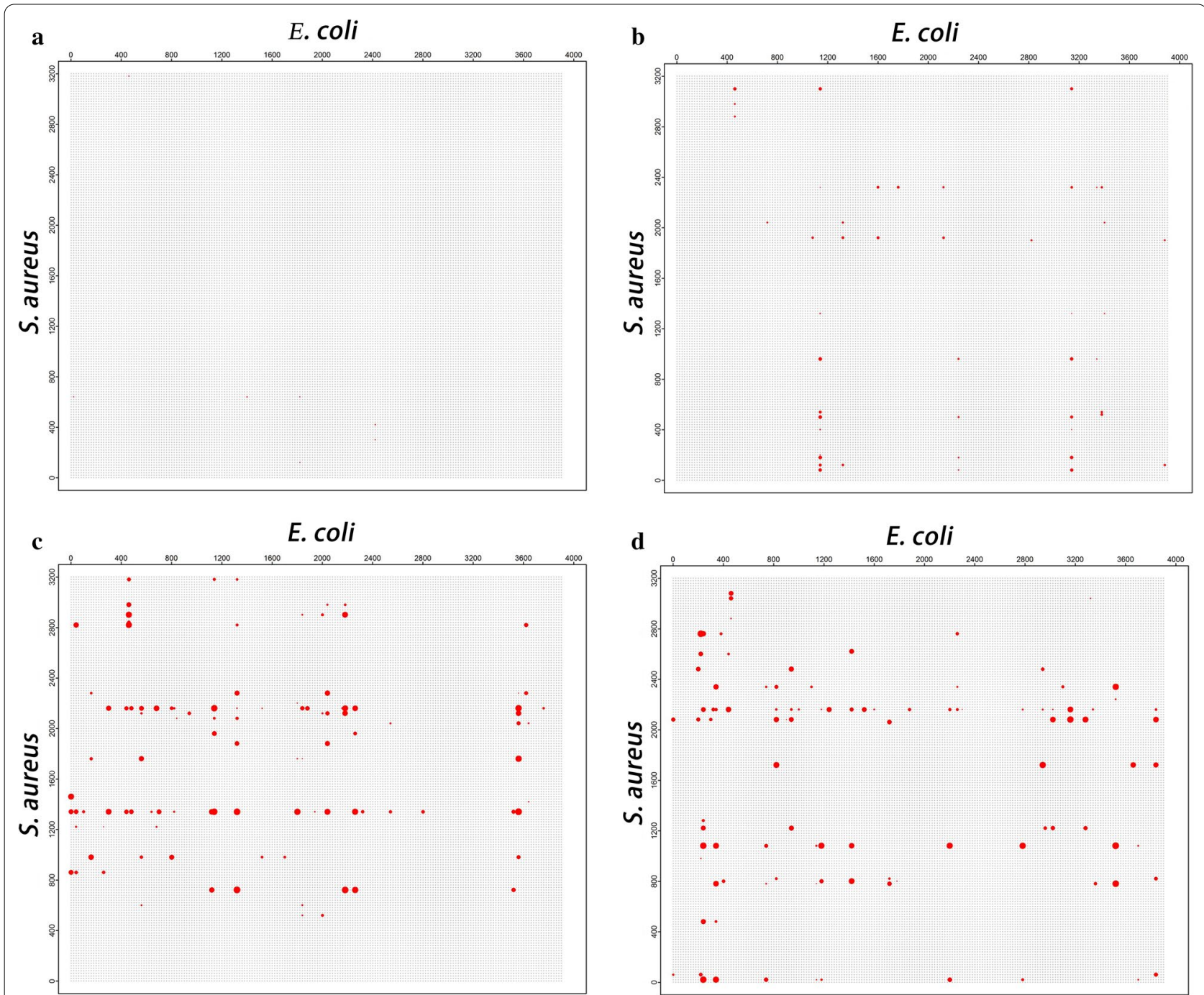

Fig. 4 Two-dimensional Manhattan plots based on growth parameters of $E$. coli and S. aureus in co-culture. a $\lambda$ parameter; $\mathbf{b} R$ parameter; $\mathbf{c} A$ parameter; $\mathbf{d} s$ parameter

pleiotropic QTLs for leaf growth trajectories can be performed based on a dynamic mapping model, which has not been applied to bacteria yet. Therefore, in this study we extended the application of this model, which is based on growth parameters of GWAS, to the study of interactions between E. coli and S. aureus.

In this research, we found some significant genes such as $y j j W, t h r C, k e f C, f t s A, w z c$ and $y e i I$, which were reported in previous studies (He et al. 2017; Jiang et al. 2018). Besides, more significant genes were identified in this study including dnaK, tatD, rclR, ftsA, ftsK, aceE, fepA in E. coli, and $s d r D$, scdA in S. aureus. Gene dnaK encodes ATP-dependent enzyme DnaK and plays an important role in the heat shock response (Collet et al. 2018). The stress response is not the only function of
DnaK, which also has a significant role in maintaining normal growth in E.coli (Ghazaei 2017). Gene tatD encodes DNA-repairing exonuclease that not only digest chromosomal DNA during apoptosis but also process damaged DNA during DNA repair. Chen et al. (2014) demonstrated that TatD-knockout strains were less resistant to the DNA damaging and were sensitive to $\mathrm{H}_{2} \mathrm{O}_{2}$. Gene $r c l R$ encodes $\mathrm{RclR}$ as a transcriptional activator, contributing to the ability of E. coli to survive $\mathrm{HOCl}$ stress (Parker et al. 2013). These three genes can regulate bacterial activities when they are in a negative environment. In addition, there are many genes that play important roles in cell growth and metabolism, such as $f t s A$ and $f t s K$ encodes FtsA and FtsK, respectively. FtsK is present as a hexamers and plays a key role 
Table 1 Significantly important functional genes in co-culture

\begin{tabular}{|c|c|c|c|c|c|}
\hline Gene ID & Gene & Position & Mutation & Affected Codon & Function \\
\hline \multicolumn{6}{|l|}{ E. coli } \\
\hline B0114 & aceE & 124522 & $\mathrm{~T} \leftrightarrow \mathrm{C}$ & $\mathrm{GCT} \leftrightarrow \mathrm{GCC}$ & Pyruvate dehydrogenase $E_{1}$ component \\
\hline B4379 & yjjW & 4614704 & $\mathrm{C} \leftrightarrow \mathrm{T}$ & $\mathrm{TTG} \leftrightarrow \mathrm{TTA}$ & Putative glycyl-radical enzyme activating enzyme YjjW \\
\hline B0014 & dnak & 12384 & $\mathrm{~T} \leftrightarrow \mathrm{C}$ & $\mathrm{GGT} \leftrightarrow \mathrm{GGC}$ & Chaperone protein DnaK \\
\hline B0094 & $f t s A$ & 104986 & $C \leftrightarrow T$ & $\mathrm{ACC} \leftrightarrow \mathrm{ACT}$ & Cell division protein FtsA \\
\hline B0890 & ftsK & 935503 & $\mathrm{G} \leftrightarrow \mathrm{A}$ & $\mathrm{CCG} \leftrightarrow \mathrm{GCA}$ & Cell division DNA translocase FtsK \\
\hline B4483 & tatD & 4024120 & $\mathrm{~T} \leftrightarrow \mathrm{G}$ & $\mathrm{CTT} \leftrightarrow \mathrm{TTG}$ & $3^{\prime} \rightarrow 5^{\prime}$ ssDNA/RNA Exonuclease TatD \\
\hline B0584 & fepA & 611271 & $\mathrm{~T} \leftrightarrow \mathrm{C}$ & $\mathrm{GGA} \leftrightarrow \mathrm{GGG}$ & Ferric enterobactin outer membrane transporter \\
\hline B0305 & $r C l R$ & 320655 & $\mathrm{~A} \leftrightarrow \mathrm{T}$ & $\mathrm{GCA} \leftrightarrow \mathrm{GCT}$ & DNA-binding transcriptional activator RcIR \\
\hline \multicolumn{6}{|l|}{ S. aureus } \\
\hline SAOUHSC_00299 & $s c d A$ & 313,151 & $C \leftrightarrow G$ & $\mathrm{AGC} \leftrightarrow \mathrm{ACC}$ & Cell wall biosynthesis protein ScdA \\
\hline SAOUHSC_01368 & $\operatorname{trpD}$ & $1,313,228$ & $\mathrm{~T} \leftrightarrow \mathrm{A}$ & $\mathrm{TCC} \leftrightarrow \mathrm{ACC}$ & Anthranilate phosphoribosyltransferase \\
\hline SAOUHSC_00545 & $s d r D$ & 554,869 & $\mathrm{C} \leftrightarrow \mathrm{T}$ & $\mathrm{GAC} \leftrightarrow \mathrm{GAT}$ & Fibrinogen-binding protein SdrD \\
\hline SAOUHSC_01219 & - & $1,169,344$ & $\mathrm{G} \leftrightarrow \mathrm{C}$ & $\mathrm{GAT} \leftrightarrow \mathrm{CAT}$ & Cell wall hydrolase \\
\hline
\end{tabular}

in coordinating cell division in the late stages of chromosome segregation and FtsA is an ATPase (Bisicchia et al. 2013; Conti et al. 2018; Galli et al. 2017), both of which assist FtsZ in cell division. Gene aceE encodes the $\mathrm{E}_{1}$ component of pyruvate dehydrogenase complex. The $\mathrm{E}_{1}$ component plays a role in the preparation phase of pyruvic acid before which enters the citric acid cycle and catalyzes the oxidative decarboxylation of pyruvate (Byung Jo et al. 2008; Nemeria et al. 2010). FepA plays a role in the transporter activity of the ferric enterobactin outer membrane, which is located in the lipid bilayer of the outer membrane of $E$. coli and belongs to the outer membrane protein of the cell wall. Its main function is to adsorb high-valent iron on the cell surface when $E$. coli is iron-deficient (Newton et al. 2010; Turlin et al. 2013). In $S$. aureus, $s d r D$ encodes fibrinogen-binding protein serine aspartate repeat containing protein $D$ (SdrD) (Askarian et al. 2016). The $s c d A$ gene expresses a cell wall biosynthesis protein that affects cell division and morphogenesis (Brunskil et al. 1997).

However, significant genes reported from this interaction analyses based on growth parameters of GWAS still require functional validation in our following research. With the application of CRISPR/Cas9 technology to bacteria in recent years (Banno et al. 2018; Chen et al. 2017, 2018; Zerbini et al. 2017), this study will be improved greatly. By constructing recombinant plasmids for knockout and mutation of target genes, it will assist in comparing phenotypic differences between wild-type and mutants to validate the effects of genes on growth. Next, we will apply CRISPR/Cas9 to verify those function genes explored in the interaction analyses.

\section{Supplementary Information}

The online version contains supplementary material available at https://doi. org/10.1186/s13568-021-01192-x.

Additional file 1: Table S1. Strain IDs.

Additional file 2: Table S2. Table S2 Growth performance of E. coli and S. aureus.

Additional file 3: Figure S1. The curve fitting for growth data of E. coli (a) and $\mathrm{S}$. aureus (b) in co-culture.

Additional file 4: Table S3. Gene annotation of E. coli and S. aureus in monoculture.

Additional file 5: Table S4. Fitting $\mathrm{R}^{2}$ of growth curves in E. coli and S. aureus in co-culture.

Additional file 6: Table S5. Gene annotation of E. coli and S. aureus in co-culture.

\section{Authors' contributions}

$X H, L J, Y J$ conceived and designed the experiments; $Y L, B L, Q Z$ performed the experiments; $S Z$ analyzed the data; $Y L, X H$ wrote the paper; $X H, L J, Y J$ contributed reagents/materials/analyses tools. All authors read and approved the final manuscript.

\section{Funding}

This work was funded by the Fundamental Research Funds for the Central Universities (2017JC05, 2015ZCQ-SW-06), Natural Science Foundation of China (31971398, 31700633) and Science and Technology Service Network Initiative (KFJ-STS-ZDTP-036).

\section{Data accessibility}

Data sequences: the raw sequence data of $E$. coli generated in this study were deposited in the NCBI Gene Expression Omnibus under Accession No. SRP074089 and the data of S. aureus under Accession No. SRP074912.

\section{Ethics approval and consent to participate}

This article does not contain any studies with human participants or animals performed by any of the authors.

\section{Competing interests}

The authors declare that they have no conflict of interest. 


\section{Author details}

${ }^{1}$ Beijing Advanced Innovation Center for Tree Breeding by Molecular Design, Beijing Forestry University, Beijing 100083, China. ${ }^{2}$ Center for Computational Biology, College of Biological Sciences and Technology, Beijing Forestry University, Beijing 100083, China. ${ }^{3}$ College of Biological Sciences and Technology, Beijing Forestry University, Beijing 100083, China.

Received: 28 November 2020 Accepted: 9 February 2021

Published online: 01 March 2021

\section{References}

Askarian F, Ajayi C, Hanssen AM, van Sorge NM, Pettersen I, Diep DB, Sollid JU, Johannessen M (2016) The interaction between Staphylococcus aureus $\mathrm{SdrD}$ and desmoglein 1 is important for adhesion to host cells. Sci Rep 6:22134. https://doi.org/10.1038/srep22134

Banno S, Nishida K, Arazoe T, Mitsunobu H, Kondo A (2018) Deaminasemediated multiplex genome editing in Escherichia coli. Nat Microbiol 3(4):423-429. https://doi.org/10.1038/s41564-017-0102-6

Berthenet E, Yahara K, Thorell K, Pascoe B, Meric G, Mikhail JM, Engstrand L, Enroth H, Burette A, Megraud F, Varon C, Atherton JC, Smith S, Wilkinson TS, Hitchings MD, Falush D, Sheppard SK (2018) A GWAS on Helicobacter pylori strains points to genetic variants associated with gastric cancer risk. BMC Biol 16(1):84. https://doi.org/10.1186/s12915-018-0550-3

Bisicchia P, Steel B, Mariam Debela MH, Lowe J, Sherratt D (2013) The N-terminal membrane-spanning domain of the Escherichia coli DNA translocase FtsK hexamerizes at midcell. MBio 4(6):e00800-e813. https://doi.org/10.1128/ mBio.00800-13

Brunskil EW, Dj BLM, Bayles KW (1997) The Staphylococcus aureus SCDA gene-a novel locus that affects cell division and morphogenesis. Microbiology 143(9):2877-2882

Byung Jo Y, Jung Ae K, Jeong Hee M, Seong Eon R, Jae-Gu P (2008) The diversity of lysine-acetylated proteins in Escherichia coli. J Microbiol Biotechnol 18(9):1529

Cairns J, Jokela R, Hultman J, Tamminen M, Virta M, Hiltunen T (2018) Construction and characterization of synthetic bacterial community for experimental ecology and evolution. Front Genet 9:312. https://doi.org/10.3389/fgene .2018 .00312

Chen PE, Shapiro BJ (2015) The advent of genome-wide association studies for bacteria. Curr Opin Microbiol 25:17-24

Chen YC, Li CL, Hsiao YY, Duh Y, Yuan HS (2014) Structure and function of TatD exonuclease in DNA repair. Nucleic Acids Res 42(16):10776-10785. https:// doi.org/10.1093/nar/gku732

Chen W, Zhang Y, Yeo WS, Bae T, Ji Q (2017) Rapid and efficient genome editing in Staphylococcus aureus by using an engineered CRISPR/Cas9 system. J Am Chem Soc 139(10):3790

Chen W, Zhang Y, Zhang Y, Pi Y, Gu T, Song L, Wang Y, Ji Q (2018) CRISPR/Cas9based genome editing in Pseudomonas aeruginosa and cytidine deaminase-mediated base editing in Pseudomonas species. iScience 6:222-231. https://doi.org/10.1016/j.isci.2018.07.024

Collet C, Thomassin JL, Francetic O, Genevaux P, Tran Van Nhieu G (2018) Protein polarization driven by nucleoid exclusion of DnaK(HSP70)-substrate complexes. Nat Commun 9(1):2027. https://doi.org/10.1038/s41467-018-04414 $-2$

Collins C, Didelot X (2018) A phylogenetic method to perform genome-wide association studies in microbes that accounts for population structure and recombination. PLoS Comput Biol 14(2):e1005958. https://doi.org/10.1371/ journal.pcbi.1005958

Conti J, Viola MG, Camberg JL (2018) FtsA reshapes membrane architecture and remodels the Z-ring in Escherichia coli. Mol Microbiol 107(4):558-576. https ://doi.org/10.1111/mmi.13902

Das K, Li J, Wang Z, Tong C, Fu G, Li Y, Xu M, Ahn K, Mauger D, Li R (2011) A dynamic model for genome-wide association studies. Hum Genet 129(6):629

Fan R, Albert PS, Schisterman EF (2012) A discussion of gene-gene and geneenvironment interactions and longitudinal genetic analysis of complex traits. Stat Med 31(22):2565-2568. https://doi.org/10.1002/sim.5495
Galli E, Midonet C, Paly E, Barre FX (2017) Fast growth conditions uncouple the final stages of chromosome segregation and cell division in Escherichia coli. PLoS Genet 13(3):e1006702. https://doi.org/10.1371/journal.pgen.1006702

Ghazaei C (2017) Role and mechanism of the Hsp70 molecular chaperone machines in bacterial pathogens. J Med Microbiol 66(3):259-265. https:// doi.org/10.1099/jmm.0.000429

Grativol AD, Marchetti AA, Wetler-Tonini RM, Venancio TM, Gatts CE, Thompson FL, Rezende CE (2017) Bacterial interactions and implications for oil biodegradation process in mangrove sediments. Mar Pollut Bull 118(1-2):221-228. https://doi.org/10.1016/j.marpolbul.2017.02.052

Hall BG (2014) SNP-associations and phenotype predictions from hundreds of microbial genomes without genome alignments. PLoS ONE 9(2):e90490. https://doi.org/10.1371/journal.pone.0090490

He X, Jin Y, Ye M, Chen N, Zhu J, Wang J, Jiang L, Wu R (2017) Bacterial genetic architecture of ecological interactions in co-culture by GWAS-taking Escherichia coli and Staphylococcus aureus as an example. Front Microbiol 8:2332. https://doi.org/10.3389/fmicb.2017.02332

Jiang L, He X, Yi J, Ye M, Sang M, Nan C, Jing Z, Zhang Z, Li J, Wu R (2018) A mapping framework of competition-cooperation QTLs that drive community dynamics. Nat Commun 9(1):3010

Kastman EK, Kamelamela N, Norville JW, Cosetta CM, Dutton RJ, Wolfe BE (2016) Biotic interactions shape the ecological distributions of Staphylococcus species. MBio. https://doi.org/10.1128/mBio.01157-16

Lees JA, Vehkala M, Valimaki N, Harris SR, Chewapreecha C, Croucher NJ, Marttinen P, Davies MR, Steer AC, Tong SY, Honkela A, Parkhill J, Bentley SD, Corander J (2016) Sequence element enrichment analysis to determine the genetic basis of bacterial phenotypes. Nat Commun 7:12797. https://doi. org/10.1038/ncomms 12797

Li J, Wang Z, Li R, Wu R (2015) Bayesian group lasso for nonparametric varyingcoefficient models with application to functional genome-wide association studies. Ann Appl Stat 9(2):640-664. https://doi.org/10.1214/15-AOAS808

Madsen JS, Sorensen SJ, Burmolle M (2018) Bacterial social interactions and the emergence of community-intrinsic properties. Curr Opin Microbiol 42:104-109. https://doi.org/10.1016/j.mib.2017.11.018

Nemeria NS, Arjunan P, Chandrasekhar K, Mossad M, Tittmann K, Furey W, Jordan F (2010) Communication between thiamin cofactors in the Escherichia coli pyruvate dehydrogenase complex $E_{1}$ component active centers: evidence for a "direct pathway" between the 4'-aminopyrimidine N1'atoms. J Biol Chem 285(15):11197-11209. https://doi.org/10.1074/jbc.M109.069179

Newton SM, Trinh V, Pi H, Klebba PE (2010) Direct measurements of the outer membrane stage of ferric enterobactin transport: postuptake binding. J Biol Chem 285(23):17488-17497. https://doi.org/10.1074/jbc.M109.100206

Ning C, Kang H, Zhou L, Wang D, Wang H, Wang A, Fu J, Zhang S, Liu J (2017) Performance gains in genome-wide association studies for longitudinal traits via modeling time-varied effects. Sci Rep 7(1):590

Parker BW, Schwessinger EA, Jakob U, Gray MJ (2013) The RcIR protein is a reactive chlorine-specific transcription factor in Escherichia coli. J Biol Chem 288(45):32574-32584. https://doi.org/10.1074/jbc.M113.503516

Pires AP, Caliman A, Laque T, Esteves FA, Farjalla VF (2015) Interaction between resource identity and bacterial community composition regulates bacterial respiration in aquatic ecosystems. Braz J Biol 75(4 Suppl 1):S150-S157. https ://doi.org/10.1590/1519-6984.07714

Rivett DW, Bell T (2018) Abundance determines the functional role of bacterial phylotypes in complex communities. Nat Microbiol 3(7):767-772. https:// doi.org/10.1038/s41564-018-0180-0

Rong M, Zheng X, Ye M, Bai J, Xie X, Jin Y, He X (2019) Phenotypic plasticity of Staphylococcus aureus in liquid medium containing vancomycin. Front Microbiol 10:809. https://doi.org/10.3389/fmicb.2019.00809

Sheppard SK, Didelot X, Meric G, Torralbo A, Jolley KA, Kelly DJ, Bentley SD, Maiden MC, Parkhill J, Falush D (2013) Genome-wide association study identifies vitamin $B_{5}$ biosynthesis as a host specificity factor in Campylobacter. Proc Natl Acad Sci U S A 110(29):11923-11927. https://doi.org/10.1073/ pnas.1305559110

Sikorska K, Lesaffre E, Groenen PJF, Rivadeneira F, Eilers PHC (2018) Genome-wide analysis of large-scale longitudinal outcomes using penalization-GALLOP algorithm. Sci Rep 8(1):6815. https://doi.org/10.1038/s41598-018-24578-7

Turlin E, Debarbouille M, Augustyniak K, Gilles AM, Wandersman C (2013) Staphylococcus aureus FepA and FepB proteins drive heme iron utilization 
in Escherichia coli. PLoS ONE 8(2):e56529. https://doi.org/10.1371/journ al.pone.0056529

van Overbeek LS, Saikkonen K (2016) Impact of bacterial-fungal interactions on the colonization of the endosphere. Trends Plant Sci 21(3):230-242. https:// doi.org/10.1016/.t.tplants.2016.01.003

Wei K, Wang J, Sang M, Zhang S, Zhou H, Jiang L, Clavijo Michelangeli JA, Vallejos CE, Wu R (2018) An ecophysiologically based mapping model identifies a major pleiotropic QTL for leaf growth trajectories of Phaseolus vulgaris. Plant J 95(5):775-784. https://doi.org/10.1111/tpj.13986

Widder S, Allen RJ, Pfeiffer T, Curtis TP, Wiuf C, Sloan WT, Cordero OX, Brown SP, Momeni B, Shou W, Kettle H, Flint HJ, Haas AF, Laroche B, Kreft JU, Rainey PB, Freilich S, Schuster S, Milferstedt K, van der Meer JR, Grobetakopf T, Huisman J, Free A, Picioreanu C, Quince C, Klapper I, Labarthe S, Smets BF, Wang H, Soyer FOS, Isaac Newton Institute F (2016) Challenges in microbial ecology: building predictive understanding of community function and dynamics. ISME J 10(11):2557-2568. https://doi.org/10.1038/ismej.2016.45
Xiao Y, Angulo MT, Friedman J, Waldor MK, Weiss ST, Liu YY (2017) Mapping the ecological networks of microbial communities. Nat Commun 8(1):2042. https://doi.org/10.1038/s41467-017-02090-2

Zerbini F, Zanella I, Fraccascia D, Konig E, Irene C, Frattini LF, Tomasi M, Fantappie L, Ganfini L, Caproni E, Parri M, Grandi A, Grandi G (2017) Large scale validation of an efficient CRISPR/Cas-based multi gene editing protocol in Escherichia coli. Microb Cell Fact 16(1):68. https://doi.org/10.1186/s1293 4-017-0681-1

\section{Publisher's Note}

Springer Nature remains neutral with regard to jurisdictional claims in published maps and institutional affiliations.

\section{Submit your manuscript to a SpringerOpen ${ }^{\circ}$ journal and benefit from:}

- Convenient online submission

- Rigorous peer review

- Open access: articles freely available online

- High visibility within the field

- Retaining the copyright to your article

Submit your next manuscript at $\boldsymbol{\sim}$ springeropen.com 